\title{
Mandatory childhood vaccination: Should Norway follow?
}

\section{Espen Gamlund ${ }^{\mathrm{a}}$, Karl Erik Müller ${ }^{\mathrm{b}}$, Kathrine Knarvik Paquet ${ }^{\mathrm{c}}$, and Carl Tollef Solberg ${ }^{\mathrm{d}}$}

a Department of Philosophy, University of Bergen, espen.gamlund@uib.no

${ }^{b}$ Department of Clinical Science, University of Bergen, and Institute of Bioscience, University of São Paulo, Brazil; Department of Internal Medicine, Drammen hospital,post@kem.priv.no

${ }^{c}$ University of Bergen, knarvikkathrine@gmail.com

${ }^{\mathrm{d}}$ Bergen Centre for Ethics and Priority Setting (BCEPS), Department of Global Public Health and Primary Care (IGS), University of Bergen, carl.solberg@uib.no

DOI: http://dx.doi.org/10.5324/eip.v14i1.3316

(cc) BY This is an open access article distributed under the terms of the Creative Commons Attribution 4.0 International License, which permits unrestricted use, distribution, and reproduction in any medium, provided the original author and source are credited.

Systematic public vaccination constitutes a tremendous health success, perhaps the greatest achievement of biomedicine so far. There is, however, room for improvement. Each year, 1.5 million deaths could be avoided with enhanced immunisation coverage. In recent years, many countries have introduced mandatory childhood vaccination programmes in an attempt to avoid deaths. In Norway, however, the vaccination programme has remained voluntary. Our childhood immunisation programme covers protection for twelve infectious diseases, and Norwegian children are systematically immunised from six weeks to sixteen years of age. In this article, we address the question of whether our country, Norway, should make the childhood vaccination programme mandatory. This question has received considerable public attention in the media, yet surprisingly little academic discussion has followed. The aim of the article is to systematically discuss whether it is morally justified to introduce a mandatory childhood vaccination programme in Norway. Our discussion proceeds as follows: We begin by presenting relevant background information on the history of vaccines and the current Norwegian childhood vaccination programme. Next, we discuss what we consider to be the most central arguments against mandatory childhood vaccination: the argument from the standpoints of parental rights, bodily integrity, naturalness, mistrust, and immunisation coverage. After that, we examine the central arguments in favour of mandatory childhood vaccination from the standpoints of harm, herd immunity, and as a precautionary strategy. We conclude that there are convincing moral arguments in favour of adopting a policy of mandatory childhood vaccination in Norway.

Keywords: autonomy, harm principle, herd immunity, parental rights, precautionary approach 


\section{Introduction}

Vaccination has a long history. Vaccines against smallpox have been described in India in the $16^{\text {th }}$ century and were later introduced in England by the physician Edward Jenner. There is also a long history of scepticism about vaccines. In the $18^{\text {th }}$ century, vaccine hesitancy was reported in both the United States and in Europe, with objections similar to those we face today, including the intrusion of privacy, the harm of bodily integrity, and the misuse of power over the working class by the ruling class. This hesitancy led to some early examples of mandatory vaccination, such as the smallpox vaccination programme in the USA (Stern \& Markel 2005).

In retrospect, public vaccination has constituted a tremendous health success, perhaps the greatest achievement of biomedicine so far. It has led to a vast decline in devastating and potentially deadly diseases such as whooping cough, polio, mumps, measles, and rubella. Moreover, smallpox has been eradicated, and there is even hope for the eradication of polio in the future. Today, it is estimated that vaccines prevent 2-3 million deaths annually, and even more people are protected from disease.

Nevertheless, there is room for further improvement. Each year, an additional 1.5 million deaths could be avoided with enhanced immunisation coverage (WHO 2019a). However, vaccine hesitancy is reported from all around the world, and scepticism about vaccines is growing (Lancet 2019). In fact, the World Health Organization (WHO) has listed vaccine hesitancy as one of the ten most pressing threats to global health in the year 2019 (WHO 2019a).

The vaccination programmes in Europe range from mandatory systems in France and Italy, to a semi-mandatory programme in Czechia and a completely voluntary programme in Norway (Bozzola et al. 2018, Paul \& Loer 2019). The programmes also differ in what vaccinations are included (see Table 1 for the Norwegian programme). Although children are automatically enrolled for immunisation in Norway, all vaccinations are voluntary, and there are no official repercussions for opting out of the programme (NIPH 2018). If parents decide not to vaccinate their children, they can reject the vaccines during their child's appointments in the public health clinic. ${ }^{1}$ A written note from the parents is sufficient for an opt-out for school-age children. No further justification is needed.

The Norwegian childhood immunisation programme covers protection against twelve infectious diseases, and Norwegian children are systematically immunised from six weeks to sixteen years of age (NIPH 2018). Table 1 below presents an overview of the Norwegian childhood immunisation programme.

In recent years we have seen outbreaks of potentially deadly diseases like measles in many countries around the world (WHO, 2019b). This has led some countries to introduce a policy of mandatory childhood vaccination (Ward, Colgrove, \& Verger 2018). The question we ask in this article is whether Norway should follow other countries and make their vaccination programme mandatory. This question has received considerable public attention in the media in recent years, yet little academic discussion has followed. In what follows, we discuss the most central arguments for and against mandatory vaccination. We begin with the arguments against mandatory vaccination, from the standpoints of parental rights, bodily integrity, naturalness, mistrust, and immunisation coverage. After that, we examine the most central arguments in favour of mandatory vaccination, from the 
standpoints of the harm argument, herd immunity, and as a precautionary strategy. We conclude that there are convincing moral arguments in favour of adopting a policy of mandatory child vaccination in Norway. ${ }^{2}$

Table 1. The Norwegian Childhood Immunisation Programme

\begin{tabular}{|c|c|c|c|}
\hline $\begin{array}{c}\text { Pathogens vaccinated } \\
\text { against }\end{array}$ & $\begin{array}{c}\text { Abbreviation } \\
\text { of Vaccine }\end{array}$ & Started & $\begin{array}{c}\text { Current } \\
\text { vaccination } \\
\text { programme }\end{array}$ \\
\hline Mycobacterium tuberculosis & $\mathrm{BCG}^{\mathrm{I}}$ & 1947 & $\begin{array}{l}1 \text { dose for } \\
\text { children at } \\
\text { risk of } \\
\text { infection, } \\
\text { given at } 6 \\
\text { weeks }\end{array}$ \\
\hline $\begin{array}{l}\text { Corynebacterium diptheriae, } \\
\text { Clostridium tetani, Bordetella } \\
\text { pertussis, poliovirus, } \\
\text { Haemophilus influenzae type B, } \\
\text { Hepatitis B }\end{array}$ & $\begin{array}{l}\text { (DTP-IPV- } \\
\text { Hib-HepB) }\end{array}$ & 2016 & $\begin{array}{l}3,5,12 \\
\text { months }\end{array}$ \\
\hline $\begin{array}{l}\text { Corynebacterium diptheriae, } \\
\text { Clostridium tetani, Bordetella } \\
\text { pertussis, poliovirus }^{3}\end{array}$ & $(\mathrm{DTP}-\mathrm{IPV})^{\mathrm{II}}$ & 1952 & 7 years \\
\hline $\begin{array}{l}\text { Corynebacterium diptheriae, } \\
\text { Clostridium tetani, Bordetella } \\
\text { pertussis, Poliovirus }\end{array}$ & $(\mathrm{dTP}-\mathrm{IPV})^{\mathrm{III}}$ & 2013 & 15 years \\
\hline Streptococcus pneumoniae & & 2006 & $\begin{array}{l}3,5,12 \\
\text { months }\end{array}$ \\
\hline $\begin{array}{l}\text { Measles virus, mumps virus, } \\
\text { rubella virus }\end{array}$ & MMR & 1983 & $\begin{array}{l}15 \text { months } \\
11 \text { years }\end{array}$ \\
\hline Human papillomavirus & $\mathrm{HPV}$ & $\begin{array}{l}2009 \\
2018 \text { for } \\
\text { boys }\end{array}$ & 12 years \\
\hline Rotavirus & & 2014 & $\begin{array}{c}6 \text { weeks } \\
3 \text { months }\end{array}$ \\
\hline
\end{tabular}

Table 1: This table presents an overview of the Norwegian childhood immunisation programme. Listed are the pathogens vaccinated against, the abbreviations/names of the vaccines, the year the vaccine was introduced to the programme, and the age at which it is given (NIPH 2018). ${ }^{\mathrm{I}} B C G$

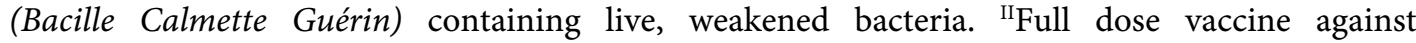

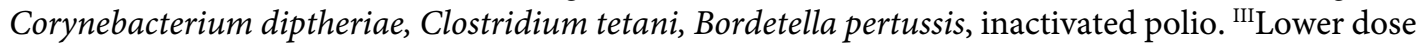
vaccine for Diphtheria, Tetanus, acellular Pertussis. Full dose Inactivated Polio vaccine. 


\section{Arguments against mandatory childhood vaccination}

Several arguments are relevant in discussing the introduction of a mandatory childhood vaccination programme in Norway. We have selected what we consider to be the most convincing arguments on each side of the table. The arguments that we examine against mandatory childhood vaccination are concerned with parental rights, children's bodily integrity, the naturalness of disease, mistrust in the health system, and immunisation coverage.

\section{Parental rights}

In Norway, parents have the final say with respect to whether or not their children should receive vaccines. It is therefore relevant to discuss the rights of parents with regard to vaccines.

At least two aspects concerning parental rights are important to consider in this context. First, parents' special relationship with their children is grounded in a special interest in their children's well-being. Moreover, this special interest is based on certain rights that parents have with respect to their children. These parental rights are underpinned by a liberal principle of respect for persons and their basic freedom and rights to live individual lives (Brennan 2018). For example, this liberal principle protects parents' right to decide what school their children should attend or what religion they will be raised in. Along these lines, one can argue that the decision of whether or not to vaccinate one's child is similar to decision-making regarding school, religion and the like. By this line of reasoning, parents should have a right to decide whether or not their children should receive vaccines. If parents, for whatever reason, wish not to have their children vaccinated, they should have a right to refuse vaccination. This is the status quo situation in Norway.

Second, parents may be permitted to refuse vaccination of their children based on a principle of parental partiality. According to this principle, parents are entitled to give greater weight to the interests and well-being of their own children than to the interests and well-being of other children. This principle comes into play in the case of vaccination because of the nature of herd immunity. Herd immunity is the indirect protection of a communicable disease that occurs when a sufficient percentage of the population becomes immune to the infection in question (Fine et al. 2011, University of Oxford 2019). Although such herd immunity (which we shall return to later), is a morally relevant matter when discussing vaccine refusal, a parent normally has the right to give greater importance to the interest of their own children than to the interest of others. Thus, if a parent believes it is in their child's best interest not to be vaccinated, then they should be allowed to refuse vaccines regardless of its impact on herd immunity.

Both of these aspects concerning parental rights have some plausibility, yet we do not think they succeed in grounding a parental right to refuse child vaccination. Even though parents might make use of their parental right to refuse vaccination with the laudable intention of protecting their children, this choice may end up going against the children's interests. Evidence strongly suggests that children benefit from routine vaccination, in the sense that unvaccinated children have a much higher risk of acquiring infectious diseases than their vaccinated peers (Colgrove 2006, Omer et al. 2009). We acknowledge that most, if not all, parents want the best for their children, and in most areas of life parents are better qualified 
than anyone else to know their child's best interests. Medical decision-making is, however, an exception to this rule. In this case, parents are generally not better qualified than their physicians, and thus they have a strong reason to trust the advice given to them by their physicians. Thus, the choice of whether or not to vaccinate one's child would seem to be an example of such medical decisionmaking. ${ }^{4}$

In cases where parents are unqualified to make adequate decisions about the interests or well-being of their children, better-qualified people should have a say. For instance, Norwegian adults are currently allowed to refuse any medical treatment they do not want. For example, adult Jehovah's Witnesses might refuse blood transfusions for themselves. This policy can be justified on the basis of a liberal principle of respect for persons and their autonomy. From a liberal standpoint, it is not permissible for the state to prohibit everything it regards as morally problematic or wrong. Even if we think adult Jehovah's Witnesses are deeply mistaken in refusing blood transfusions, they should be allowed to make such a decision for themselves. In Norway, Jehovah's Witnesses are not allowed to refuse blood transfusion for their children. Current practice presupposes that there is a morally relevant distinction between what parents should be allowed to do for themselves, and what they are allowed to do for their children. This law is reasonable in that it protects children from becoming innocent victims in the hands of their parents.

A similar line of thought is reasonable when it comes to routine childhood vaccination. The law respects parents' decisions for their children in most cases, except where the child's health, well-being or life is at risk (Diekema 2004). To refuse vaccination is to prevent the child from acquiring individual immunity, putting the child at risk of contracting a preventable disease, which ultimately places the child's health in jeopardy. It can be argued that children have a right to be protected against vaccine-preventable diseases and harmful choices made by their parents (Colgrove 2006). Mandatory childhood vaccination could be viewed as society's way of protecting this right.

A second reason to limit parents' right to decide for their children is if this decision is harmful to the interests of others (Gamlund 2015, Moen $2015 \mathrm{a} \& \mathrm{~b}$ ). An unvaccinated child constitutes a risk of harm to others, due to the negative impact on herd immunity. Everyone takes advantage of herd immunity, and one cannot choose not to take advantage of it; herd immunity is therefore considered a public good. For this reason, parental partiality is not a valid counterpoint to mandatory vaccination. That is to say, herd immunity is of such importance that implementing mandatory childhood vaccination may be a justifiable means of reaching this goal.

In sum, although the argument for parental rights in many cases gives parents a right to make important decisions for their children, this right should not protect the choice of whether or not to vaccinate.

\section{Bodily integrity}

Another argument against mandatory vaccination proceeds from the fact that children, like adults, have a constitutional right to bodily integrity, which gives them a right to avoid unwanted physical intrusions (Hill 2015). Child vaccination is not necessarily categorised as a breach of this right due to parents' right to consent (Norwegian legislation 1999), but vaccination is likely to be experienced as an 
unwanted physical intrusion by some children. When vaccinating, there are several potential intrusions to a child's bodily integrity to consider, including the pain of the injection, the inability of small children to understand the painful injection's purpose, and the inability of older children (who understand its purpose), to refuse the injection. The existence of such physical intrusions invites the question of whether the benefits of vaccination (both individual and public) can override the child's right to bodily integrity.

It is crucial to consider a child's bodily integrity in all cases involving medical interventions. Here it is important to remember that vaccines are beneficial in two ways: (i) Individual immunity protects those vaccinated from fatal diseases, and (ii) every injection contributes to the establishment and upholding of herd immunity. It can be argued that these benefits far exceed the possible negative consequences of violating a child's bodily integrity (Krantz, Sachs \& Nilstun 2004).

Respecting a child's fear of pain and autonomy is important, but not to the extent of avoiding a health intervention that is significantly beneficial to both the individual and society as a whole. Compared to the alternative of contracting a communicable disease, the pain that accompanies the injection certainly is a lesser evil. Various measures can be taken to protect the child's integrity when vaccinating, such as making the injections less painful and less frightening for the child. ${ }^{5}$ In the end, vaccination will protect the child's interest in being healthy, which in turn protects the child's bodily integrity insofar as it reduces the likelihood of eventual hospitalisation (and further pain from needle sticks).

\section{Naturalness}

The starting point for the third argument against mandatory childhood vaccination is a concern about naturalness. Some people would argue that infectious diseases are a natural part of life (Dube et al. 2013). Vaccines are thought to interfere with natural events and are, accordingly, unnatural and should be avoided.

Some vaccine-hesitant individuals seem to believe that the vaccine-preventable diseases are only mild or harmless and that it is preferable for immunity to develop naturally in response to a disease rather than from unnaturally invoked immunisation (Salmon et al. 2005, Dube et al. 2013,). Moreover, some parents believe that their children are not susceptible to the infectious diseases in question, making the corresponding vaccines seem as unnatural (unnecessary) to their child as carrying an EpiPen would be to someone who is not susceptible to anaphylactic shock (Omer et al. 2009, Williams 2014). With the exception of a few single cases of measles, no large outbreaks of vaccine-preventable diseases in Norway have occurred since introducing the voluntary vaccines in the childhood vaccination programme (NIPH 2018). Some parents apparently believe that it is better to act passively and let nature take its course - to contract the diseases or not - to avoid the risks associated with vaccination. ${ }^{6}$

Indeed, a few of the targeted communicable diseases in our vaccination programme may pass uneventfully in high-income countries (i.e., rotavirusgastroenteritis). However, other diseases within the protection-programme may cause more serious complications (e.g., tuberculosis, measles) (Maldonado 2002, Giubilini 2017). Recall that WHO estimates that about 1.5 million further deaths from communicable diseases could be prevented worldwide through immunisation (WHO 2019a). Fatal diseases that are seemingly eradicated tend to reappear when 
immunisation coverage drops. The safest way to protect against these "natural" diseases is through vaccine-immunisation (Bustreo 2017).

Moreover, the fact that something is natural indicates nothing about whether it is beneficial or valuable. Hurricanes and tsunamis are both natural and rare events and most, if not all, parents would protect their children from such disasters. Similarly, one could ask why they should not protect their children from contracting a natural communicable disease? Our point is that it is problematic to draw moral conclusions from assumptions about what is natural. Most diseases are natural. If we were morally obliged to let nature take its course, then this would indeed challenge our justification for having a healthcare system in the first place. We know that many people, both in Norway and in other countries, process scientific facts and information poorly and in irrational ways (David et al. 2010). This applies to vaccination information and practices as well. The fact that some parents view the naturalness of diseases as an argument not to vaccinate provides reason to ensure that the decision of whether or not to vaccinate is not left to the parents alone.

\section{Mistrust}

The naturalness argument is unconvincing. However, a much more pressing concern is whether introducing mandatory childhood vaccination in Norway would create mistrust in our healthcare system. In societies where individual freedom trumps the interest for the common good, mandatory vaccination programmes may be viewed as unnecessary and spark opposition to the mandate altogether. For one thing, individual freedom must be weighed against public benefits (Salmon et al. 2006). For another, some parents are already exempting their children from vaccines due to mistrust in the government (Salmon et al. 2005, Williams 2014). Thus, forcing these parents to vaccinate their children may cause even more mistrust instead of the intended medical benefits.

Liberal democracies like Norway have a presumption against laws that either prohibit or mandate specific actions and practices. The liberal ideal is that citizens should, as much as possible, be free to make decisions concerning their own lives, and the state should not interfere unnecessarily in this freedom. Against this background, we should expect reactions when laws are introduced that limit the rights or liberties of citizens to make decisions concerning their own lives.

Fortunately, Norway enjoys high levels of trust, and it is reasonable to assume that Norwegian citizens trust their institutions to make well-informed and reasonable decisions about matters concerning their lives. This belief is based on Norwegian citizens' willingness to contribute to a well-functioning welfare state, including the healthcare system. On the other hand, evidence suggests that Norwegian adults who show less trust in the Norwegian health authorities are also less willing to get vaccinated (Arnesen et al. 2018). What is more, we know that jurisdictions that force people to contribute to a public good are more successful in countries with significant concern for the protection of the common good (Salmon et al. 2006).

It is hard to predict the exact consequences of implementing a policy of mandatory childhood vaccination in Norway. We understand that individuals who fear that mandatory vaccination will negatively affect people's trust in our government and healthcare system. However, the relevant question to ask is how 
likely we will experience a situation where people develop mistrust as a result of being forced to vaccinate their children. This is an important empirical question that we cannot address in its full length here. That being said, when introducing such a mandated policy, it is important to think about how the policy is justified to the wider public. In this light, it is crucial to emphasise the fact that mandatory vaccination is a public good which we all benefit from, and something to which we all should contribute.

Countering this view, some people would object that the willingness to vaccinate children is already high in a country like Norway. After all, we currently enjoy herd immunity with approximately $95 \%$ immunisation coverage for several of the infectious diseases in question. Some scholars have suggested that while there are compelling reasons for introducing mandatory childhood immunisation programmes in other countries, this is not so for a country like Norway with its high immunisation rates (Salmon et al. 2006). Thus, one can argue that since we do not need to force the remaining $5 \%$ to achieve sufficient coverage, introducing mandatory childhood vaccination in Norway is misguided and may instead have the opposite effect of creating mistrust in the population. ${ }^{7}$ A sceptic may add that as long as there is herd immunity, failure to vaccinate one's child will not harm others.

We think this objection fails to recognise several essential points. Opting out of vaccinating children incurs no direct harm, but rather increases the risk of harm (independent of herd immunity). Even if herd immunity exists in your area, deciding against vaccination may contribute to the risk of harm to others in at least one of the following ways: First, we may not be sure that the herd immunity applies to the whole area of Norway or just to parts of the country. We know that some communities have significantly lower immunisation coverage than others and that some areas have been below the threshold for herd immunity (NIPH 2019). Second, herd immunity is not a fixed and stable state of affairs, but rather vulnerable to demographic changes. For instance, we know that Norwegians travel a lot, and the herd immunity for a given disease in Norway may not likewise exist in countries visited by Norwegians. In addition, tourists coming to Norway may not be vaccinated. Unvaccinated migrants add to the concern in this regard. Third, we may regard the $5 \%$ above herd immunity as an insurance. A $99 \%$ rate of immunisation coverage is, all things considered, better insurance than $95 \%$ coverage, even if we assume that the threshold for herd immunity for a given disease is $94 \%$. Fourth, we may grant that our ambition should be to eradicate communicable diseases whenever possible. We have already managed to eradicate smallpox, and the same might be achievable with polio (WHO 2019c). Fifth, individual choices not to vaccinate seldom occur in isolation. One free-riding parent may motivate other parents to do the same. Finally, related to the previous point, one can argue that justice and solidarity require us to vaccinate our children, and people who opt out fail to uphold justice and solidarity. ${ }^{8}$

The foregoing points serve to show some of the benefits of maintaining high levels of herd immunity. Even though Norway currently enjoys herd immunity, we believe this should not delay mandatory vaccination efforts. When introducing a policy of mandatory vaccination, the government would be advised to emphasise the benefits of both individual and herd immunity, rather than the fact that the policy implies that parents are being forced to vaccinate their children. If this 
approach is successfully implemented, we think it is reasonable to assume that the Norwegian population will welcome a policy of mandatory vaccination, or at least not oppose it to the extent that it creates a problem of mistrust.

\section{Immunisation coverage}

We will consider one final objection to mandatory vaccination. Will a shift from voluntary to mandatory childhood vaccination in Norway actually increase the overall immunisation coverage? If not, some may object that we have no good grounds to implement a mandatory program.

This objection raises a valid point, but one we believe it is possible to counteract. Here it is important to distinguish between two claims with regard to the relationship between mandatory vaccination and immunisation coverage. According to a weak claim, implementing mandatory vaccination is an insurance mechanism against reduced immunisation coverage. According to a strong claim, implementing mandatory vaccination is a means of increasing the overall immunisation coverage in Norway. The weak claim is surely plausible. Here the justificatory basis for introducing mandatory vaccination is that it will guard against reduced immunisation coverage. In Norway, the coverage is quite high, but for reasons mentioned in the previous section, the possibility of reduced overall immunisation coverage in the future poses a danger. Mandatory vaccination provides insurance against this scenario.

The strong claim goes one step further to suggest that introducing mandatory vaccination will increase the probability of higher immunisation coverage overall. How plausible is this claim? According to one EU report, no connection was found between immunisation coverage in countries where vaccination is mandatory and in countries where it is not. ${ }^{9}$ However, some - or even most - of the countries that have introduced a mandatory policy have quite likely done so because they want to achieve higher immunisation coverage (D'Ancona et al. 2019). Interestingly, evidence shows that the introduction of a mandatory childhood vaccination programme resulted in an increase in overall immunisation coverage in countries like Italy, France, and several states in the USA (Omer et al. 2009, D'Ancona et al. 2019). To our knowledge, no countries have experienced a reduction in immunisation coverage as a result of introducing a mandatory policy.

To be sure, we are in a state of uncertainty with regard to what will happen in Norway if we introduce a mandatory vaccination programme. As already mentioned, Norway is fortunate to enjoy high immunisation rates. In accordance with the weak claim, we believe a strong justificatory basis for introducing a policy of mandatory vaccination in Norway is to avoid a decrease in the immunisation coverage. Mandatory vaccination can guard against factors that might negatively affect the vaccine rates, and in this sense it is an important insurance mechanism. In our view, even if the weak claim provides the primary justificatory basis for switching from voluntary to mandatory vaccination in Norway, we believe it is not unreasonable to expect that such a switch will also increase the overall immunisation coverage. Given that increased coverage has happened in Italy, France, and several states in the USA, then it could also happen here. Moreover, such an increase in overall immunisation coverage would likely contribute to a more even distribution of immunisation coverage for the different subpopulations or municipalities in Norway. ${ }^{10}$ 


\section{Summary}

To summarise, we have presented five arguments against introducing a mandatory childhood vaccination programme in Norway. We have shown that there are convincing objections to all five arguments. We now turn to consider the arguments in favour of mandatory vaccination.

\section{Arguments in favour of mandatory childhood vaccination}

The arguments that we will discuss in favour of mandatory vaccination are the harm principle, the importance of herd immunity, and the value of a precautionary approach.

\section{The harm principle}

One argument in favour of implementing a mandatory vaccination programme takes the harm principle as its point of departure. According to John Stuart Mill: "The only purpose for which power can be rightfully exercised over any member of a civilised community, against his will, is to prevent harm to others" (Mill 1859: 22). That is to say, according to Mill, power can potentially be rightfully exercised over people if it prevents harm to others. When parents vaccinate their children, they achieve two benefits at the same time: they provide their own children with individual immunity, and they prevent harm to others by contributing to herd immunity. Thus, Mill's harm principle may lend support to a policy of mandatory childhood vaccination, insofar as vaccinating children is an effective means of preventing harm to others (Hussain et al. 2018).

Some opponents to vaccination may object that the vaccines themselves do not come without risk of harm. The most common side effects of injectable vaccines are local redness, swelling, and pain. In fewer than $10 \%$ of vaccinated individuals, restlessness, irritability and discomfort may occur (NIPH 2018). Some vaccines such as the MMR and the pneumococcal vaccine - carry a $10 \%$ risk of developing a fever. ${ }^{11}$

We should, however, compare this harm (i.e., the side effects) to the alternative of contracting the disease in question. For every case of measles worldwide, there is about a one in twenty chance of developing pneumonia and a further one in one thousand chance of developing encephalitis, which can leave the child deaf or with a severe intellectual disability (CDC 2019). What is more, one in three thousand cases of measles results in death. By comparison, the risk of severe side effects like encephalitis or severe allergic reactions from the MMR vaccine is one in a million. For diphtheria, the risk of a fatal outcome is as high as one in ten (CDC 2018b). And for pertussis and tetanus, the mortal risk is one in two hundred and three in one hundred, respectively. By contrast, there are no reported deaths for the diphtheria, tetanus and polio vaccine (DTP) (Maldonado 2002). Thus, when comparing the possible side effects of vaccines to the effect of their correspondent diseases, the benefits far outweigh the risk (see e.g., Andre et al. 2008). ${ }^{12}$

Another objection against the harm principle is that vaccines do not prevent actual harm, but only possible harm. What is more, perhaps the harm principle does not apply for childhood vaccination since it is not granted that non- 
immunised individuals will spread disease. In response to this objection, consider our elaboration on the following case by Jamrozik and colleagues: There is a line of 100 non-vaccinated opt-outs ( $\mathrm{T}$ ) that all transmit a communicable disease to one another in the respective order 1 to 100 , before T100 infects an immunosuppressed victim V. Suppose that all 100 individuals have had a similar exposure to immunosuppressed individuals and that they have taken the same precautions (hand-washing etc.). Who is responsible for the infection of V? Seen in retrospect, had T100 obtained a vaccine, then V would not have been infected. Moreover, there is a direct transmission between $\mathrm{T} 100$ and V. Thus, according to a traditional liability model, T100 is most blameworthy. However, it is also the case that T99 and every other member of this chain of transmission are necessary for $\mathrm{V}$ to become infected. In this latter sense, all individuals (T1 to T100) are equally blameworthy with regard to the transmission of V (Jamrozik, Handfield \& Selgelid 2016). Along similar lines, in a population with a large proportion of opt-outs, only a small percentage of them bring a risk of breaching herd immunity, but even so, there are reasons to think that all opt-outs are equally responsible. Vaccination should be mandatory in order to reduce the risk of people harming one another by breaching herd immunity and by being vectors in transmitting diseases. This risk reduction would, in turn, justify state intervention in accordance with the harm principle.

\section{Herd immunity}

As citizens in our society, we enjoy the benefits of certain public goods, such as national security and clean air. Herd immunity is another example of such a public good because we all benefit from it to an equal degree. The most effective way for citizens to contribute to herd immunity is through individual vaccination. Moreover, it can be argued that contributing to herd immunity is fair because (i) the cost is low, (ii) the risk of complications is minimal, and (iii) in most cases, the cost is the same for everybody who is contributing (Navin 2013). Furthermore, as a matter of fact, some people cannot acquire individual immunity through vaccination. Vulnerable individuals include the very young, older people and people who are sick. These populations depend on the vaccine efforts of the other members of our society. A concern for the vulnerable thus provides strong reasons of fairness in favour of mandatory vaccination (Giubilini 2019). If enough people opt out of our Norwegian childhood vaccination programme, this may result in the cessation of herd immunity, which in turn will increase the risk of an outbreak of preventable disease. Thus, severe harm and even death could result if vaccination remains a personal choice for parents rather than an obligation.

One can argue that those who fail to contribute to a public good thereby take unreasonable advantage of the efforts of those who make their fair contribution to this good. These people may be characterised as free riders. Free riders are people who take advantage of a public good without contributing to it (Hardin 1968). The opportunity to free-ride - i.e., choosing not to vaccinate and still benefiting from herd immunity - needs to be limited for several reasons. From a moral point of view, we have established that herd immunity is a public good, and anybody taking advantage of it without contributing is acting unfairly. From a medical point of view, free-riding increases the risk of infection in the community and puts the vulnerable members of the community at a heightened risk of contracting illnesses (Omer et al. 2009, Browne 2016). 
As previously mentioned, herd immunity is upheld when around $95 \%$ of the population is immunised (this percentage-threshold is slightly higher or lower depending on the disease in question). People who are sceptical of vaccines will sometimes make the case that their own child should be part of the $5 \%$ unvaccinated group. The question of who can be allowed into the unvaccinated group is important, and it needs to be discussed further in connection with the process of implementing a policy of mandatory childhood vaccination. On the one hand, there is the question of whether certain exemptions may be valid, based for instance on sensitive personal issues, or religious or personal convictions that vaccinating is somehow wrong. On the other hand, such exceptions must be weighed against the risk of losing herd immunity. However, such exemptions are likely to do more harm than good (Phadke et al. 2016, Hussain et al. 2018). A particular problem with allowing such free-riding for certain groups lies in the clustering of these individuals. People with religious or personal exemptions tend to belong to the same religious congregations or social groups. The clustering of unvaccinated children poses an even higher risk of a disease outbreak, as well as more severe complications for the vulnerable groups (Omer et al. 2009, Lantos, Jackson \& Harrison 2012). ${ }^{13}$

We believe that the most reasonable costs to consider in discussing a policy of mandatory childhood vaccination are the risks involved. For healthy individuals, the risk of harm is very low. For particular individuals, such as immunosuppressed children, the risk is much higher. As a starting point, free-riding should only be reserved for those who cannot be vaccinated for medical reasons. Opting out for any other reason than medical ones should only rarely be considered if a society is well within the limits of herd immunity, which is usually not the case (Hussain et al. 2018).

There is evidence that people are genuinely concerned for others when it comes to vaccines. One recent representative survey experiment on the Norwegian population asked whether information about herd immunity could help us achieve sufficient coverage. The results suggested that a concern for others highly influences people's decision about whether or not to vaccinate. Thus, as emphasised earlier, it is reasonable to assume that highlighting the collective benefits of vaccination could increase immunisation coverage (Arnesen et al. 2018).

\section{A precautionary strategy}

Research and modern technology have allowed us to reduce morbidity, mortality and costs connected to vaccines and communicable disease (Bustreo 2017). The vaccines in the Norwegian programme have gone through extensive testing to make them safe and to provide the best results in protecting against diseases. Moreover, in Norway, everybody has access to free immunisation and the administration of vaccines in safe settings (NIPH 2018). Some would argue that vaccines in the childhood programme should be kept voluntary and participation boosted through education and positive incentives. Given that no considerable outbreaks of preventable diseases in Norwegian communities have occurred in recent years and that we currently enjoy herd immunity in most areas, many people in Norway hold the view that our current voluntary immunisation programme is good enough as it is today. 
This line of thinking would support what we could call a wait-and-see strategy, according to which we should not adopt a policy of mandatory vaccination in the current situation marked by herd immunity, but rather wait until the situation changes for the worse. The idea behind this strategy would be that there is no reason to implement a policy that is currently not needed and which could potentially have negative effects, such as creating mistrust in our society. ${ }^{14}$ Alternatively, we could choose a precautionary strategy, according to which it is better to adopt a policy of mandatory vaccination safely now and avoid a potentially dangerous situation where we fall below the threshold of herd immunity. This latter strategy could be backed up by the knowledge we have of outbreaks of serious diseases around the world. For example, measles was close to being eradicated in the USA in 2000, but there were nearly 700 cases across the USA a few years ago, and 2019 is on track to have the highest number of measles cases since 2000 (Browne 2015, CDC 2018a, Gostin, Ratzan \& Bloom 2019). In 2018, there were more than 140000 deaths as a result of measles worldwide; most of them were children under five years of age (WHOb).

We think a precautionary strategy should be preferred over a wait-and-see strategy. First of all, with a voluntary programme in place, there is no way of guaranteeing sufficient immunisation coverage to prevent the spread of communicable diseases within Norway or across national borders. The way diseases like measles and other preventable diseases are spreading in countries where vaccines are not as accessible provides reasons in favour of a precautionary strategy in Norway (Bustreo 2017, WHO 2019a \& d). Secondly, although implementing mandatory policies requires justification in a liberal democracy like Norway, we believe the risk of harm resulting from outbreaks of a disease like measles would be so severe that it should trump the potential costs of enforcing vaccination. The most relevant potential cost to consider in this case is public mistrust in the government and the health care system. But, as discussed earlier, although implementing a policy of mandatory vaccination runs the risk of negatively affecting the high levels of trust characteristic of the Norwegian society, there are also the risks associated with potential outbreaks of deadly diseases like measles. These risks need to be balanced against each other. We believe the risk of mistrust should not be overstated. As mentioned above, evidence may suggest that highlighting the collective benefits of vaccination could increase immunisation coverage (Arnesen et al. 2018).

Thirdly, in discussing a precautionary strategy, it is crucial to keep in mind that the reasons parents choose not to vaccinate change over time and are highly influenced by social networks. There is no data showing which methods are effective and which methods are not (Williams 2014). To be clear, if an alternative, less intrusive, and equally effective method of preventing the harm of a communicable disease outbreak existed, a voluntary programme would be desirable over a mandatory one. But the fact is that one will almost certainly achieve better protection against the diseases by making vaccination mandatory by law than with policies that rely on persuasion and education alone (Colgrove 2006, Kata 2010, Betsch 2012, Sinclair et al. 2019, Smith \& Majumder 2019).

To conclude, several of the vaccine-preventable diseases are highly contagious and very hard to contain in non-immunised populations. With a safe and successful solution to the possible spread of severe disease available, it seems reasonable to 
implement a precautionary strategy instead of Norway's current wait-and-see strategy.

\section{Summary}

We have presented three arguments in favour of a mandatory childhood vaccination programme in Norway, which together provide strong reasons in support of implementing a policy of mandatory childhood vaccination in Norway.

\section{Sanctions}

One important issue needs mentioning before we round off our discussion. This concerns what sanctions should be used against those who do not conform to the law, i.e., individuals who choose not to vaccinate their children. Other countries with mandatory vaccination policies have adopted varied sanctions. For example, in Germany and Italy, parents have to prove that their children have been vaccinated or they will be fined, and unvaccinated children risk being denied access to school (D'Ancona et al. 2019). The question is how Norway should approach sanctions if childhood vaccination becomes mandatory?

For a start, we should distinguish between sanctions directed against the children and sanctions directed against the parents. If children are denied access to kindergarten or school because their parents chose not to vaccinate them, then they suffer doubly: first, they fail to receive individual immunity, and second, they are cut off from school. We believe this form of sanction is problematic and should be avoided. Since the parents are responsible for vaccinating their children, they should be sanctioned for failing to conform to the law, and not their children.

What sanctions can parents of unvaccinated children expect to receive? We propose a step-by-step system of sanctions. In Norway, vaccination is administrated by the public health care system. Prior to school age, children are routinely called in to receive vaccines at the health station. When entering school, they are routinely vaccinated through the school. We propose to continue this practice if mandatory vaccination is implemented. Good information about the benefits of vaccines should remain a key element. However, the system should be revised to make it harder for parents to opt out of the vaccine programme. Currently, there is no need for parents to provide any justification for opting out. With the revised model, parents should be required to offer reasons why they refuse to vaccinate their children, and only medical exemptions will be accepted. If other exemptions are allowed, such as religious ones, then this again might negatively affect the immunisation rates (Salmon et al. 2006).

What about those who still do not conform to the law? To be sure, the Norwegian government can never force parents to vaccinate their child. Implementing a mandatory vaccination policy must, however, imply a willingness to impose some form of penalty on those who do not follow the law. One such penalty could be the withdrawal of welfare benefits, such as the monthly child support. This had some positive effect in Australia (Trent 2019). Depending on how successful these measures are, other forms of sanction may be considered.

From a liberal standpoint, one can defend mandatory vaccination on the grounds that it does not constitute an unreasonable paternalistic infringement of 
people's freedom and liberties. Recall that the analogous examples here would be mandatory use of car seat belts and motorcycle helmets (Giubilini and Savulescu 2019). These are simple preventive measures which do not constitute a large infringement and which at the same time protect people's interest in avoiding harm. In addition, such mandatory policies have positive social economic effects, because fewer people die or need hospital care.

Having said all of this, it is important to emphasise that we are not willing to impose mandatory childhood vaccination at all costs. Whether or not we should impose mandatory childhood vaccination depends on the costs involved, and these costs must be weighed against the benefits. If the costs exceed the benefits in the form of distrust in our health care system, which in turn leads to falling immunisation rates, then keeping the programme voluntary would be preferable at least until we have reason to think that the situation has changed. As we have tried to show in this article, however, we are optimistic that implementing mandatory childhood vaccination will not have the effect of sowing distrust.

\section{Concluding remarks}

The aim of this article has been to discuss whether making the Norwegian childhood vaccination programme mandatory is morally justified. We examined five arguments against mandatory vaccination: the argument for parental rights, the argument for bodily integrity, the argument for naturalness, the argument of mistrust, and the argument of immunisation coverage. Although these arguments highlight relevant and crucial concerns - especially the worry that a mandatory policy would create mistrust in society - we believe they do not offer a convincing case against implementing a policy of mandatory childhood vaccination in Norway. We then considered three arguments in favour of implementing a mandatory vaccination policy: the harm argument, the argument for herd immunity, and the precautionary strategy argument. We concluded that a programme of mandatory childhood vaccination in Norway is justified because the potential benefits outweigh the disadvantages.

This story does not end here. Critical issues remain that deserve further attention before a policy of mandatory vaccination can be put into place. Proper information and suitable incentives for the Norwegian population are vital for a successful mandatory childhood vaccination programme in our country. The issue of how to introduce a mandate is highly sensitive, and more research is needed to draw firm conclusions about the connection between voluntary actions, a mandate and immunisation coverage in Norway. Moreover, further discussion on how a mandatory vaccination programme should be implemented is necessary.

\section{Acknowledgements}

An earlier version of this article was presented at Mancept Workshops in Political Theory, University of Manchester and at the Department of Philosophy, University of Bergen in 2015. In 2019, we presented a draft at the Practical Philosophy Workshop, Department of Philosophy, University of Bergen. Thanks to the participants at these venues for their constructive comments and feedback. We 
would also like to thank Lars Moen and Preben Sørheim for their very helpful written comments on an earlier version of this manuscript. Finally, we thank two anonymous reviewers of this journal for their valuable comments.

\section{Notes}

${ }^{1}$ In this article, the term parent refers to anyone with legal authorisation to make medical decisions on behalf of a child.

${ }^{2}$ We need to make some critical clarifications at the outset. In this article, we discuss whether it is morally justifiable to make the Norwegian childhood vaccination programme mandatory. We do not discuss vaccines in other programmes. This programme consists only of vaccines that have gone through extensive testing, and are the same as those used in most countries around the world, ensuring a high level of safety with regard to the contents of the vaccines. We do not include the question of mandatory vaccination for adults. Moreover, we will not discuss any of the legal or legitimacy aspects of a possible mandatory programme, nor do we consider the question of what incentives are needed for such a mandate to be enforced. These matters involve a complexity beyond the ethical discussion of mandatory vaccination undertaken here, placing a discussion of such additional measures outside the scope of this article (see, e.g., Paul \& Loer 2019). Insofar as Norway were to consider implementing a mandatory childhood vaccination programme, it would involve mandatory vaccinations for the general population of Norwegian children. This would only allow exemptions in the subpopulations where vaccination is contraindicated in an absolute sense. Examples of absolute contraindications for vaccination are having a history of severe anaphylactic reaction to a vaccine or one of its components, children having an impaired immune response (live vaccines) and BCG vaccination in HIV-seropositive children (Galazka, Lauer \& Keja 1984).

${ }^{3}$ Clarification of DTP introduction to the vaccination programme: The DTP vaccine has been available in Norway and part of the Norwegian childhood immunisation programme since 1952. The last dose for 15-year-olds was introduced in the school year of 13-14, and the six-valent vaccine where the DTP is given together with three other vaccines in one injection was introduced in 2016. ${ }^{4}$ One objection to our line of reasoning is that the state cannot justify mandatory vaccination because there is a danger that they are mistaken about the risk and benefit of such vaccines. Perhaps vaccines are more dangerous than we think, or perhaps the benefit is not all that great. Just as parents may sometimes be mistaken about what is good for their children, so may the state (represented by health personnel) be mistaken about how important and safe vaccines are. As pointed out to us by Elling Ulvestad, some historical examples challenge the assumption that "physicians know best." Perhaps physicians should be humble regarding the fact that knowledge evolves, and that current health interventions may be proven wrong in the future. One classic example would be the invention of lobotomy, which was honoured with a Nobel Prize. Another and more moderate example is the case of Pandemrix in Norway in 2009, in which mass vaccination was initiated against a disease in reaction to a swine flu epidemic that most experts knew was relatively harmless. This mass vaccination was performed with a vaccine that had not been tested, and a certain controversy arose in the aftermath as to whether this mass 
vaccination harmed certain children with narcolepsy. To this point, we believe that the vaccines in the childhood vaccination programme are relevantly different from these two cases. For one thing, all the vaccines in the programme have been tested; for another, the vaccines in the programme have been widely used in many countries and over time. In a situation where reasonable doubt exists among competent persons (e.g., doctors) about the risks and benefits associated with vaccines, we contend that such reasonable doubt would support the parental right to have the final say with respect to whether or not their children should receive the vaccines in question. Since we are not in such a situation of uncertainty today, and strong evidence documents the safety of the relevant vaccines, physicians recommending these vaccines can be trusted.

${ }^{5}$ Non-prescription numbing creams and band-aids can be applied before an injection. Also, certain vaccines can be given orally. Moreover, if an infant is breastfeeding while being immunised, they will feel less pain from the needle stick (Mangat et al. 2018). Similarly, an older child who is educated and more prepared for an upcoming unfamiliar event is likely to experience less fear (Hsieh et al. 2017). ${ }^{6}$ There are, for instance, Facebook groups where parents seek contact with other parents with children who have contracted a disease, such as measles, in the hope that these children can infect their own children.

${ }^{7}$ We thank Elling Ulvestad for pressing us to emphasise these points.

${ }^{8}$ We return to this point in our discussion of the argument for herd immunity.

${ }^{9}$ An EU report which examines the relationship between mandating vaccination and coverage states that: "This comparison cannot confirm any relationship between mandatory vaccination and rates of childhood immunisation in the EU/EEA countries". See Asset Reports (2016).

${ }^{10}$ We know that certain municipalities in Norway lack herd immunity for several infectious diseases. For instance, the immunisation coverage for measles among sixteen-year-olds is below the threshold for herd immunity (95\% coverage) in 77 Norwegian municipalities (NIPH 2019).

${ }^{11}$ The common misconception of a link between the MMR vaccine and side effects like autism has been debunked (Taylor et al. 2014).

12 The effectiveness of the most central vaccines in the Norwegian childhood vaccination programme - like the MMR, diphtheria, and pertussis - is higher than $99 \%$ (Ada 2001). No vaccine can achieve $100 \%$ effectiveness, but immunisation through vaccination is still the safest way to acquire protection for those communicable diseases that are included in the Norwegian childhood vaccination programme, compared with any other preventive measure (Maldonado 2002).

${ }^{13}$ Vulnerable people (those unable to be vaccinated) tend to experience more severe complications from communicable diseases in the communities where the vaccination rate is low or in communities with clusters of unvaccinated people, than those who merely choose not to be vaccinated. See Omer et al. (2009) and Lantos, Jackson and Harrison (2012).

${ }^{14}$ For an argument for enhancing the trust in vaccination procedures, rather than mandating the vaccination programme, see Ulvestad (2015). 


\section{References}

Ada, G. (2001). Vaccines and Vaccination. The New England Journal of Medicine 345(14), 1042-1053. https://doi.org/10.1056/NEJMra011223

Andre, F. E., Booy, R., Bock, H. L., Clemens, J., Datta, S. K., John, T. J., Lee, B. W., Lolekha, S., Peltola, H., Ruff, T. A., Santosham, M., \& Schmitt, H. J. (2008). Vaccination greatly reduces disease, death and inequity worldwide. Bull World Health Organ, 86(2), 140-146. https://doi.org/10.2471/BLT.07.040089

Arnesen S., Bærøe, K., Cappelen, C., \& Carlsen, B. (2018). Could information about herd immunity help us achieve herd immunity? Evidence from a population representation survey experiment. Scandinavian Journal of Public Health, 46(8), 854-858. https://doi.org/10.1177\%2F1403494818770298

Asset Reports. (2016). Compulsory vaccination and rates of coverage immunization in Europe. Asset Reports.

Bozzola, E., Spina, G., Russo, R., Bozzola, M., Corsello, G, \& Villani, A. (2018). Mandatory vaccinations in European countries, undocumented information, false news and the impact on vaccination uptake: the position of the Italian pediatric society. Italian Journal of Pediatrics, 44(1), 67. https://doi.org/10.1186/s13052-018-0504-y

Brennan, J. (2018). A libertarian case for mandatory vaccination. Journal of Med Ethics, 44(1), 37-43. https://doi.org/10.1136/medethics-2016-103486

Browne, K. (2015). Measles, Vaccination, and the Tragedy of the Commons. The Hastings Center. https://www.thehastingscenter.org/measles-vaccinationand-the-tragedy-of-the-commons/ (Accessed September 17 ${ }^{\text {th }}, 2019$ ).

Browne, K. (2016). The Measles and Free Riders, California's Mandatory Vaccination Law. Cambridge Quarterly of Healthcare Ethics, 25(3), 472-478. https://doi.org/10.1017/S0963180116000116

Bustreo, F. (2017). Embrace the facts about vaccines, not the myths. The World Health Organization. https://www.who.int/news-room/commentaries/detail/ embrace-the-facts-about-vaccines-not-the-myths (Accessed September $17^{\text {th }}$, 2019).

Center for Disease Control and Prevention (CDC). (2018a). Measles cases and outbreaks. 26 September 2018. https://www.cdc.gov/measles/casesoutbreaks.html (Accessed September 17 ${ }^{\text {th }}, 2019$ ).

Center for Disease Control and Prevention (CDC). (2018b). Complications. https://www.cdc.gov/diphtheria/about/complications.html (Accessed October $\left.1^{\text {st }}, 2019\right)$.

Center for Disease Control and Prevention (CDC). (2019). Complications of Measles. https://www.cdc.gov/measles/symptoms/complications.html (Accessed October 1 $1^{\text {st }}, 2019$ ).

Colgrove, J. (2006). The Ethics and Politics of Compulsory HPV Vaccination. The New England Journal of Medicine, 355, 2389-2391. https://doi.org/10.1056/ NEJMp068248

D’Ancona, Fortunato, Claudio D’Admario, Francesco Maraglino, Giovanni Rezza and Stefania Iannazzo. 2019. The law on compulsory vaccination in Italy: an update 2 years after the introduction. Eurosurveillance 24, 25. https://doi.org/ 10.2807/1560-7917.ES.2019.24.25.1900371 
David, D., Lynn, S. J., \& Ellis, A. (Eds.) (2010). Rational and Irrational Beliefs: Research, Theory, and Clinical Practice. Oxford: Oxford University Press. https://doi.org/10.1093/acprof:oso/9780195182231.001.0001

Diekema, D.S. (2004). Parental Refusals of Medical Treatment: The Harm Principle as Threshold for State Intervention. Theoretical Medicine, 25(4), 243-264. https://doi.org/10.1007/s11017-004-3146-6

Dube, E., Laberge. C., Guay, M., Bramadat, P., Roy, R., \& Bettinger, J. A. (2013). Vaccine hesitancy: An overview. Human Vaccines \& Immunotherapeutics, 9(8), 1763-1773. https://doi.org/10.4161/hv.24657

Fine, P., Eames, K., \& Heymann, D. L. (2011). Herd Immunity: A Rough Guide. Clinical Infectious Diseases, 52(7), 911-916. https://doi.org/10.1093/cid/ cir007

Galazka, A.M., Henderson, R.H., Lauer, B.A., \& Keja, J. (1984). Indications and contraindications for vaccines used in the Expanded Programme on Immunization. Bulletin of the World Health Organization, 62(3), 357-366. https://www.ncbi.nlm.nih.gov/pmc/articles/PMC2536309/pdf/bullwho00092 -0013.pdf

Gamlund, E. (2015). Vi må stille krav til foreldrene. Bergens Tidende, 28 April 2015: 36. (Accessed September 17 $7^{\text {th }}, 2019$ ).

Giubilini, A. (2017). Italy has introduced mandatory vaccinations - other countries should follow its lead. The Conversation. http://theconversation.com/italyhas-introduced-mandatory-vaccinations-other-countries-should-follow-itslead-78576 (Accessed September 17 $7^{\text {th }}, 2019$ ).

Giubilini, A. (2019). The Ethics of Vaccination. Oxford: Palgrave Macmillan. https://doi.org/10.1007/978-3-030-02068-2.

Gostin, L. O., Ratzan, S. C., \& Bloom, B. R. (2019). Safe Vaccinations for a Healthy Nation: Increasing US Vaccine Coverage Through Law, Science, and Communication. JAMA, 321(20), 1969-1970. https://doi.org/10.1001/jama. 2019.4270

Guibilini, Alberto, and Julian Savulescu. 2019. Vaccination, Risk, and Freedom: The Seat Belt Analogy. Public Health Ethics, online first, e1-13. https://doi.org/10.1093/phe/phz014

Hardin, G. (1968). The Tragedy of the Commons. Science, 162(3859), 1243-1248. https://doi.org/10.1126/science.162.3859.1243

Hill, B. J. (2015). Constituting Children's Bodily Integrity. Duke Law Journal, 64(7), 1295-1362. https://pdfs.semanticscholar.org/2299/b7997489f1d1b7bf313b7 edf569501fc0e42.pdf

Hsieh, Y. C., Cheng, S. F., Tsay, P. K., Su, W. J., Cho, Y. H., \& Chen, C. W. (2017). Effectiveness of Cognitive-behavioral Program on Pain and Fear in Schoolaged Children Undergoing Intravenous Placement. Asian nurses res, 11(4), 261-267. https://doi.org/10.1016/j.anr.2017.10.002

Hussain, A., Ali, S., Ahmed, M., \& Hussain, S. (2018). The Anit-vaccination Movement: A Regression in Modern Medicine. Cureus, Journal of Medical Science, 10(7), e2919: 1-8. https://doi.org/10.7759/cureus.2919

Jamrozik, E., Handfield, T., \& M. J. Selgelid. (2016). Victims, vectors and villains: are those who opt out of vaccination morally responsible for the death of others? Journal of Medical Ethics, 42(12), 762-768. https://doi.org/10.1136/ medethics-2015-103327 
Krantz, I., Sachs L., \& Nilstun T. (2004). Ethics and vaccination. Scandinavian Journal of Public Health, 32(3), 172-178. https://doi.org/10.1080/140349403 10018192

Lancet (2019). Vaccine hesitancy: A generation at risk. The Lancet, 3, 281. https://doi.org/10.1016/S2352-4642(19)30092-6

Lantos, J. D., Jackson M. A., \& Harrison, C. J. (2012). Why we should eliminate personal belief exemptions to vaccine mandates. Journal of Health Politics, Policy and Law, 37(1), 131-140. https://doi.org/10.1215/03616878-1496038

Maldonado, Y. A. (2002). Current Controversies in Vaccinations: Vaccine Safety. JAMA, 288(24), 3155-3158. https://doi.org/10.1001/jama.288.24.3155

Mangat, A. K., Oei, J. L., Chen, K., Quah-Smith, I., \& Schmölzer, G. M. (2018). A review of Non-Pharmacological Treatments for Pain Management in Newborn Infants. Children, 5(10), 1-12. https://doi.org/10.3390/children 5100130

Mill, J. S. (1859). On Liberty. London.

Moen, L. J. K. (2015a). En plikt til å vaksinere? Foreldres rett til å si nei. Civita. https://www.civita.no/assets/2015/12/Civita-notat_32_2015.pdf (Accessed September $\left.17^{\text {th }}, 2019\right)$.

Moen, L. J. K. (2015b). A Duty to Vaccinate? Parents' Right to Say No. University of Auckland, 1-41.

Navin, M. (2013). Resisting moral permissiveness about vaccine refusal. Public Affairs Quarterly, 27(1), 69-85.

Norwegian Institute of Public Health. (2018). Childhood Immunisation Programme. Norwegian Institute of Public Health. https://www.fhi.no/en/id/ vaccines/childhood-immunisation-programme/ (Accessed September 17th, 2019).

Norwegian Institute of Public Health. (2019). Statistikk for barnevaksinasjon. Norwegian Institute of Public Health. https://www.fhi.no/hn/helseregistreog-registre/sysvak/barnevaksinasjon---statistikk/ (Accessed December 11 ${ }^{\text {th }}$, 2019).

Norwegian legislation. (1999). Lov om pasient- og brukerrettigheter. \$4-4 Samtykke på vegne av barn. Lovdata. https://lovdata.no/lov/1999-07-02-63/\$4-4

Omer, S. B., Salmon D. A., Orenstein, W. A., Dehart, P., \& Halsey, N. (2009). Vaccine Refusal, Mandatory Immunization, and the Risks of VaccinePreventable Diseases. New England Journal of Medicine, 360(19), 1981-1988. https://doi.org/10.1056/NEJMsa0806477

Paul, K. T., \& Loer, K. (2019). Contemporary vaccination policy in the European Union: tensions and dilemmas. Journal of Public Health Policy, 40(2), 166179. https://doi.org/10.1057/s41271-019-00163-8

Phadke V. K., Bednarczyk R. A., Salmon D. A. \& Omer S. B. (2016). Association Between Vaccine Refusal and Vaccine-Preventable Diseases in the United States: A Review of Measles and Pertussis. JAMA, 315(11), 1149-1158. https://doi.org/10.1001/jama.2016.1353

Salmon, D. A., Moulton, L. H., Omer, S. B., DeHart, M. P., Stokley, S., \& Halsey, N. A. (2005). Factors Associated With Refusal of Childhood Vaccines Among Parents of School-aged Children: A Case-Control Study. Arch Pediatr Adolesc Med, 159(5), 470-476. https://doi.org/10.1001/archpedi.159.5.470 
Salmon, D. A.,Teret, S. P., MacIntyre, C. R., Salisbury, D., Burgess, M. A., \& Halsey, N. A. (2006). Compulsory vaccination and conscientious and philosophical exemptions: past, present, and future. The Lancet, 367(9508), 436-442. https://doi.org/10.1016/S0140-6736(06)68144-0

Sinclair, D. R., Grefenstette, J. J., Krauland, M. G., et al. (2019). Forecasted Size of Measles Outbreaks Associated With Vaccination Exemptions for Schoolchildren. JAMA Netw Open, 20192(8), e199768. https://doi.org/10.1001/jamanetworkopen.2019.9768

Smith, T. C., \& Majumder, M. S. (2019). Science Should Drive Vaccine Policy. JAMA Netw Open, 20192(8), e1910170. https://doi.org/10.1001/ jamanetworkopen.2019.10170

Stern, A. M. \& Markel, H. (2005). The history of vaccines and immunization: familiar patterns, new challenges. Health Affairs, 24(3), 611-621. https://doi.org/10.1377/hlthaff.24.3.611

Taylor, L. E., Swerdfeger, A. L., \& Eslick, G. D. (2014) Vaccines are not associated with autism: An evidence-based meta-analysis of case-control and cohort studies. Vaccine, 32(29), 3623-3629. https://doi.org/10.1016/j.vaccine.2014. 04.085

Trent, M. J., E. J. Zhang., A. A. Chughtai, C. R. MacIntyre. (2019). Parents opinions towards the No Jab, No Pay policy in Australia. Vaccine 37, 5250-5256. https://doi.org/10.1016/j.vaccine.2019.07.066

Ulvestad, E. (2015). Vaksinasjon - tillit eller tvang? Tidsskrift for Den norske legeforening, 135, (12-13), 1111. https://doi.org/10.4045/tidsskr.15.0579

University of Oxford. (2019). Herd Immunity (Herd Protection). The Vaccine Knowledge Project, Oxford Vaccine Group. http://vk.ovg.ox.ac.uk/vk/herdimmunity (Accessed September 17th, 2019).

Ward, J. K., Colgrove, J., \& Verger, P. (2018). Why France is making eight new vaccines mandatory. Vaccine, 36, (17): 1801-1803. https://doi.org/10.1016/ j.vaccine.2018.02.095

WHO. (2019a). Ten threats to global health in 2019. The World Health Organization. https://www.who.int/emergencies/ten-threats-to-globalhealth-in-2019 (Accessed September 17 ${ }^{\text {th }}, 2019$ ).

WHO. (2019b). Measles and Rubella Surveillance Data. https://www.who.int/ immunization/monitoring_surveillance/burden/vpd/surveillance_type/activ e/measles_monthlydata/en/ (Accessed October $\left.1^{\text {st }}, 2019\right)$.

WHO. (2019c). Polio eradication initiative. https://www.who.int/countries/eth/ areas/immunization/pei/en/

WHO. (2019d). Measles. https://www.who.int/en/news-room/fact-sheets/detail/ measles (Accessed September 25th, 2019).

Williams, S. E. (2014). What are the factors that contribute to parental vaccinehesitancy and what can we do about it? Human, Vaccines \& Immunotherapeutics, 10(9), 2584-2596. https://dx.doi.org/10.4161\%2Fhv. 28596. 